\title{
ANÁLISIS EXPLORATORIOS SOBRE ARTEFACTOS LÍTICOS DE LA LOCALIDAD DE PUNTA MEDANOSA (PROVINCIA DE SANTA CRUZ)
}

LUCÍA C. MAZZITELLI"

\section{RESUMEN}

El objetivo general de este trabajo es el de aportar al conocimiento de la organización tecnológica de los grupos cazadores recolectores que habitaron la Costa Norte de la Provincia de Santa Cruz, en el marco de las ocupaciones y re-ocupaciones registradas para el Holoceno medio y tardío en el área. En particular, este trabajo se centra en la búsqueda y determinación de variables que puedan dar cuenta de procesos de reclamación, reutilización y/o re-formatización de artefactos líticos, a partir del análisis de conjuntos artefactuales provenientes de sitios arqueológicos ubicados específicamente en la Localidad de Punta Medanosa. Se discuten aspectos tecnológicos relevantes para la comprensión de fenómenos de re-ocupación del área por parte de estas poblaciones que habrían explotado la costa de manera estacional. Se presentan los análisis realizados y resultados obtenidos a partir de estos estudios, los cuales pueden ser aplicados a otros conjuntos.

PALABRAS CLAVE: cazadores recolectores, tecnología lítica, reocupación, reclamación, fuentes de aprovisionamiento.

\section{EXPLORATORY ANALYSIS ON LITHIC ARTIFACTS FROM PUNTA MEDANOSA LOCALITY (SANTA CRUZ, PROVINCE)}

\begin{abstract}
This paper aims to contribute to the knowledge of the technological organization of northern coast of Sta. Cruz hunter gatherers, according to the occupations and re-occupations registered in this area in the middle and late Holocene. Particularly in this paper we seek to determinate the variables that can explain reclamation, reutilization and/or re-shaping of lithic artifacts, based on the analysis of lithic assemblages from Punta Medanosa locality, Santa Cruz province, Argentina. We discuss technological aspects that are important for the understanding of re-occupation phenomenon in this particular coast area that was exploited seasonally. We present the analysis and results from this research, and we recognize its applicability in other assemblages.
\end{abstract}

KEY WORDS: hunter gatherers, lithic technology, re-occupation, reclamation, raw materials source.

Becaria de Investigación de la UNLP. FCNyM, División Arqueología, Laboratorio 1. Paseo del bosque s/nº. lcmazzitelli@gmail. com. 


\section{INTRODUCCIÓN}

Los estudios realizados hasta el momento en la costa norte de la provincia de Santa Cruz (Fig. 1), han permitido delinear algunas tendencias importantes sobre las antiguas ocupaciones de grupos cazadores recolectores.

Se ha registrado un uso diferencial del litoral marino por parte de estas sociedades durante el Holoceno medio y tardío, pudiéndose determinar zonas con densidades bajas, medias y altas de materiales arqueológicos. Los sitios registrados son concheros, talleres y de entierro en general a cielo abierto, a excepción de algunos casos en aleros o cuevas. Se estableció una relación entre la presencia de restos arqueológicos y la disponibilidad de recursos como loberías, cormoraneras, bancos de moluscos, etc. Así como también entre la presencia de estos recursos y las características geomorfológicas de las costas, que condicionan su disponibilidad y accesibilidad (Castro et al. 2003).

Dentro de este sector de costa, se encuentra la Localidad de Punta Medanosa, localizada a unos $40 \mathrm{~km}$ al sur de la localidad de Puerto Deseado. Se extiende en sentido este-oeste en un área de 7 $\mathrm{km}$ de longitud y 3,5 km de ancho, y presenta una cubierta de médanos sobre su frente norte con una gran cantidad de sitios tipo conchero a cielo abierto, y de entierros tipo chenques como los registrados en el área. El sustrato medanoso del área, junto a los fuertes y abundantes vientos, le otorgan al paisaje una gran dinámica y en consecuencia la incidencia de procesos de alteración post-depositacional es muy alta. En la actualidad, es una zona visitada frecuentemente por turistas, por lo que presenta un gran impacto antrópico moderno.

Punta Medanosa, corresponde a un sector de alta densidad de materiales arqueológicos, en especial, de restos artefactuales líticos. Los análisis de ${ }^{14} \mathrm{C}$ realizados sobre muestras recolectadas en 5 sitios, indicaron fechados entre los ca 6.300 y 900 años AP (Castro et al. 2005, 2007 y 2011). Esta amplitud cronológica se corresponde con procesos de reocupación del espacio.

El objetivo general de este trabajo es aportar al conocimiento de la organización tecnológica (Nelson, 1991) de los grupos cazadores recolectores que habitaron la Costa Norte de la Provincia de Santa Cruz, en el marco de las ocupaciones y re-

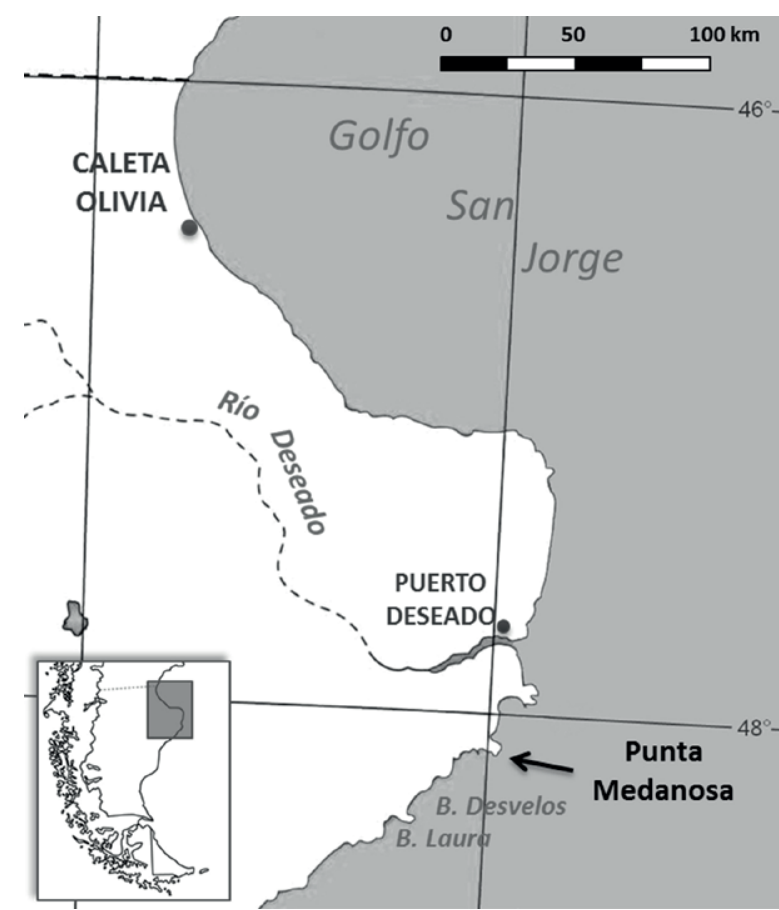

Fig. 1. Mapa de la Costa norte de Santa Cruz y ubicación de la localidad arqueológica Punta Medanosa.

ocupaciones registradas para el Holoceno Medio y Tardío en el área. En particular nos centraremos en la búsqueda y determinación de variables diagnósticas dentro de conjuntos artefactuales líticos, de procesos de reclamación, reutilización (Schiffer, 1991) y re-formatización de artefactos provenientes de la Localidad de Punta Medanosa, provincia de Santa Cruz.

Nuestra hipótesis de trabajo es que los restos artefactuales líticos acumulados por reiteradas ocupaciones se utilizaron como fuente de aprovisionamiento de materias primas y/o de instrumentos ya formatizados (Church, 1995), por lo tanto la manufactura de nuevos instrumentos y el uso de artefactos reclamados, están condicionados por las formas previamente descartadas, es decir, que podrían haber conductas sociales vinculadas al aprovechamiento de estos restos de talla descartados en ocupaciones previas como fuentes terciarias de aprovisionamiento de materias primas líticas. Las fuentes terciarias, están conformadas por importantes cantidades de materiales liticos que incluyen distintas etapas de la secuencia de producción y que por alguna razón han sido descartados, quedando durante cientos o miles 
de años como un agregado a disposición de potenciales futuros usuarios (Somonte \& Baied, 2011).

\section{PUNTA MEDANOSA}

\section{Los sitios muestreados}

Los materiales analizados en este trabajo provienen de cuatro intervenciones arqueológicas realizadas en la localidad de Punta Medanosa. Los Sitios 1, 3 y 4 corresponden a sitios sobre médanos en los que se realizaron sondeos $y$ recolecciones superficiales en grillado y fuera de cuadrícula. La Transecta 1 ("Piedra del Cura"), corresponde a la recolección de material superficial a partir de una transecta de $100 \mathrm{~m}$ de largo, por $1 \mathrm{~m}$ de ancho (aproximadamente) al NE en línea recta de la Piedra del Cura. En términos generales, los sitios conchero sobre médano corresponden a concentraciones en forma de lentes que funcionan a la vez como fijadores de los médanos, y que se van desmoronando progresivamente a medida que el viento erosiona los sedimentos que los contienen en su perímetro. La transecta, por otro lado, atraviesa la superficie de varias lentes $\mathrm{y} / \mathrm{o}$ concentraciones de diferentes materiales.

\section{La Muestra}

Para la investigación, se tomaron los materiales provenientes de las recolecciones superficiales fuera de cuadrícula, obtenidos en trabajos de campo realizados en los años 2000 y 2007. Estos materiales son la resultante de ocupaciones reiteradas de este espacio.

En la Tabla 1 se muestran los materiales recolectados. En particular los materiales superficiales recolectados fuera de cuadrícula suman un total de 761 piezas.

En la Fig. 2 se presentan los grupos tipológicos presentes en cada sitio. En términos generales los sitios 1,3 y 4 presentan características similares en cuanto a las proporciones de los grandes grupos tipológicos, distinguiéndose el conjunto proveniente de la recolección por medio de transecta, en la que la proporción de núcleos y de formas base potenciales es levemente mayor.

Esto señala una coherencia en cuanto a la recolección de materiales y datos. Las diferencias que se señalan para el conjunto de la transecta, seguramente se relacionan con el tipo de muestreo

Tabla 1. Materiales recolectados en Punta Medanosa (en cursiva se señala la muestra seleccionada para este trabajo).

\begin{tabular}{|c|c|c|}
\hline Sitio & Tipo de recolección & Total \\
\hline Piedra del Cura & Recolección superficial fuera de cuadrícula & 232 \\
\hline Total Piedra del Cura & & 232 \\
\hline \multirow{3}{*}{ Sitio 1} & Recolección superficial fuera de cuadrícula & 34 \\
\hline & Recolecciôn superficial en cuadrículas & 50 \\
\hline & Sondeo 1 & 31 \\
\hline Total Sitio 1 & & 115 \\
\hline \multirow{3}{*}{ Sitio 3} & Recolección superficial fuera de cuadrícula & 215 \\
\hline & Recolección superficial en cuadrículas & 82 \\
\hline & Sondeo 1 & 7 \\
\hline Total Sitio 3 & & 304 \\
\hline \multirow{3}{*}{ Sitio 4} & Recolección superficial fuera de cuadrícula & 280 \\
\hline & Recolección superficial en cuadrículas & 121 \\
\hline & Sondeo 1 & 17 \\
\hline Total Sitio 4 & & 418 \\
\hline Total general & & 1069 \\
\hline
\end{tabular}




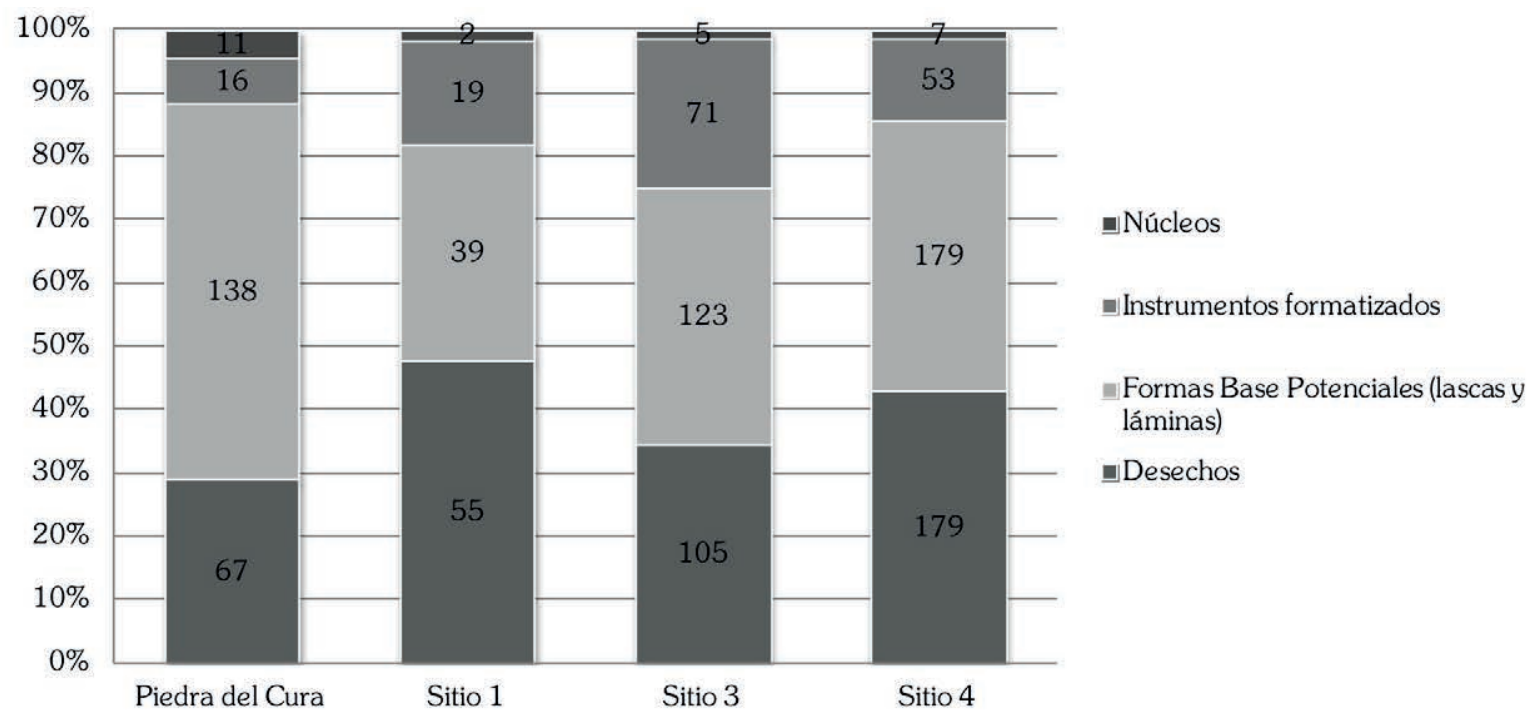

Fig. 2. Porcentajes de grupos tipológicos registrados para cada conjunto.

empleado, sobre todo si consideramos además los datos presentados en la Fig. 3, en la que pueden observarse cómo están representados los sitios según los módulos de tamaño de las piezas.

En esta figura se observa que para los tamaños medianos y grandes, la mayor porción la proporciona el conjunto de la transecta, la cual fue realizada en las zonas bajas de los médanos atravesando varias concentraciones de material. En consecuencia, es probable que el predominio de formas medianas y grandes (como núcleos, restos de núcleo y formas bases potenciales de lascas o láminas) en este conjunto se vincule a la caída de las piezas de mayor tamaño por las pendientes de los médanos, acumulándose en las zonas bajas de los mismos.

\section{METODOLOGÍA}

Desde un punto de vista metodológico, y conforme a los objetivos planteados para estos análisis, las piezas obtenidas en cuatro recolecciones de superficie en el sitio fueron consideradas como un solo conjunto. Esta muestra consta de un total de 761 piezas, las cuales fueron analizadas a ojo desnudo y con lupa binocular, es decir, que se trabajó en una escala macroscópica y de bajos aumentos.

Sobre estos artefactos se realizaron análisis tipológicos basados en los criterios propuestos por
Paunero \& Castro (2001), y Aschero (1975) y (1983). La clasificación de materias primas se hizo acorde a los criterios propuestos por Ambrústolo (2011) en su tesis doctoral. Se consideraron criterios tecno-morfo-funcionales para realizar una caracterización tipológica, registrando para cada pieza: tamaño y módulos de tamaño, características de la forma base, materia prima, tipo de forma base, grado de conservación, tipos de talón y bulbo y presencia de corteza. En cuanto a los filos, se consignó en primera instancia la presencia de filos formatizados o naturales y, en ambos casos, las características de los filos y del retoque. Para los núcleos se consignaron sus caracteres tecnológicos y morfológicos.

En todos los casos, los análisis se realizaron prestando especial atención a la morfología de los artefactos para determinar la presencia de formas reutilizadas o recicladas, con o sin cambio de función (Schiffer, 1990).

Durante el proceso de análisis se registraron también variables que consideramos pueden ser indicadoras de procesos de reclamación, reutilización y re-formatización de los artefactos líticos. De este modo, para cada una de las piezas se consignó: nivel de daño general de la pieza (presencia de microlascados y microfracturas); presencia de daños modernos (microlascados o microfracturas) fuera de los filos retocados o potencialmente utilizables y en los filos retocados 


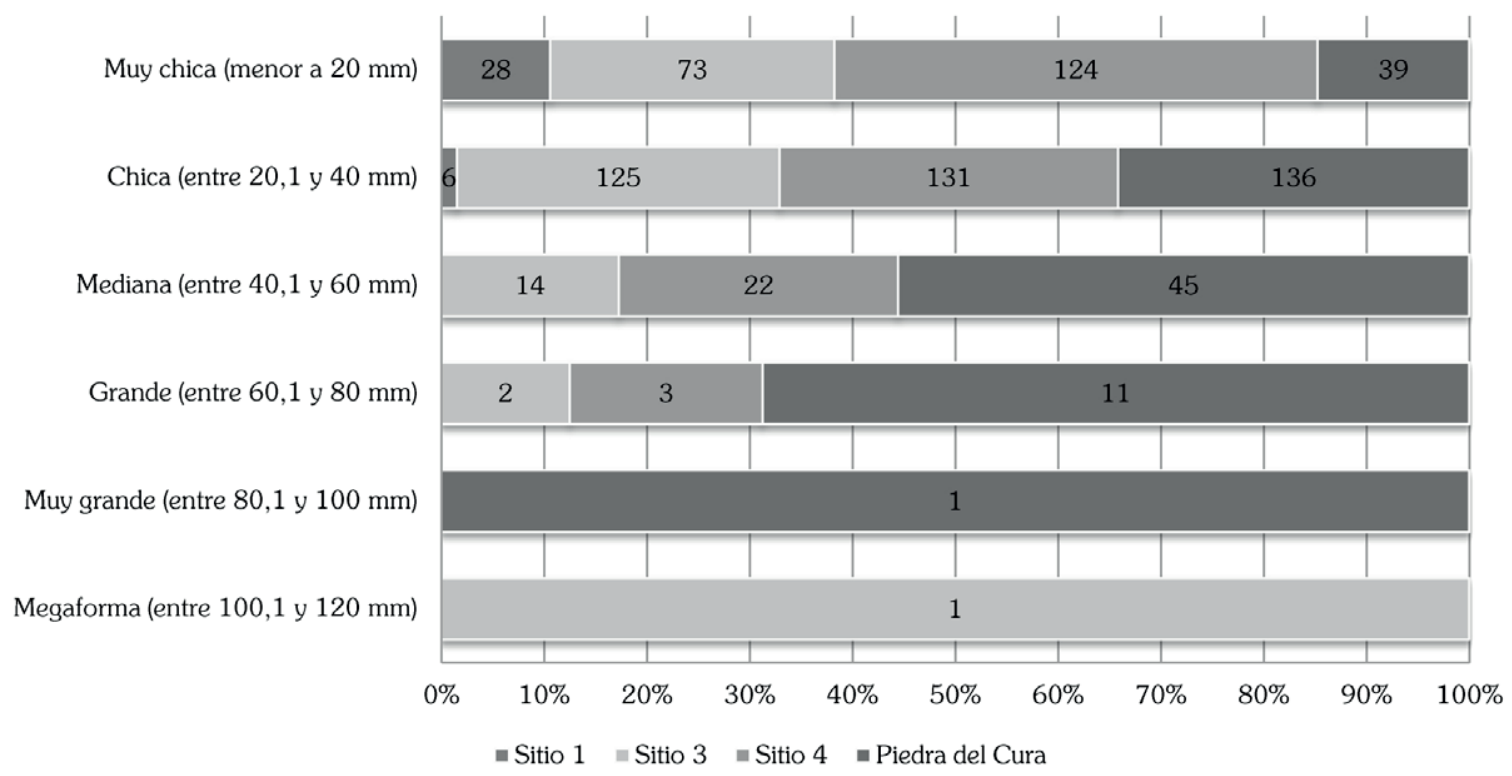

Fig. 3. Porcentajes y cantidad de piezas según los sitios en cada módulo de tamaño.

o potencialmente utilizables; presencia de pátinas; presencia de tratamiento o daño térmico; grado de embotamiento, retracción y desgaste de los filos. Estas características podrían indicar procesos tecnológicos, funcionales y post-depositacionales útiles para distinguir eventos tecnológicos o de uso separados en el tiempo.

\section{ANÁLISIS DE LA MUESTRA, RESULTADOS Y DISCUSIÓN}

En primera instancia, nos interesó saber si era posible definir variables diagnósticas para la determinación de los procesos de reclamación, reutilización y re-formatización de restos artefactuales líticos. Desde este punto de vista se generaron una serie de preguntas y expectativas para el conjunto analizado, esperando por un lado poder observar y detallar morfologías artefactuales diagnósticas, y, por otro, poder delinear variables de interés para la determinación de estos procesos. En la búsqueda de evidencias de reutilización de instrumentos, procedimos a una serie de análisis que nos llevaron a los resultados que se presentan a continuación.

En la Tabla 2 se presenta la frecuencia de subgrupos tipológicos en la muestra.

Los núcleos aparecen en una baja proporción $(2,37 \%)$ y la mitad de ellos corresponden a núcleos no agotados y potencialmente aún utilizables. $\mathrm{Si}$ estos restos de talla hubieran sido utilizados como fuente alternativa de materia prima, sería esperable que los núcleos estuvieran en su mayoría agotados, producto de la reiterada explotación de los mismos.

Observamos también una baja proporción $(9,86 \%)$ de microlascas, microesquirlas, esquirlas y lascas chicas. Este tipo de piezas pueden ser diagnósticas para la determinación de procesos de reactivación de filos y re-formatización de instrumentos líticos. Sin embargo, esta baja proporción también puede ser el resultado de las características del muestreo y de la dinámica postdepositacional del área.

Por otro lado, la morfología de los instrumentos puede ser de utilidad en la búsqueda de procesos de cambio de función y reactivación. Los instrumentos multifuncionales, y las morfologías no estandarizadas o no tipificables pueden indicar también intencionalidades en cuanto al aprovechamiento de un recurso lítico con una morfología condicionada por usos previos. Los estudios indicaron que la mayoría de los instrumentos tienen morfologías que si son tipificables (en su mayor proporción raspadores y filos formatizados), y que los instrumentos multifunción $(1,98 \%)$ y las formas no clasificables $(3,96 \%)$ se presentan en porcentajes muy bajos (Tabla 3) 
Tabla 2. Grupos y Subgrupos tipológicos representados en la muestra.

\begin{tabular}{|c|c|c|c|}
\hline Grupo tipológico & Sub grupo & $\mathrm{N}$ & $\%$ \\
\hline \multirow{5}{*}{ Desechos } & Desecho propiamente dicho & 215 & $28,25 \%$ \\
\hline & Esquirla & 40 & $5,26 \%$ \\
\hline & Lasca chica (menor a $10 \mathrm{~mm}^{2}$ ) & 34 & $4,47 \%$ \\
\hline & Microesquirla & 1 & $0,13 \%$ \\
\hline & Microlasca & 1 & $0,13 \%$ \\
\hline Total Desechos & & 290 & $38,11 \%$ \\
\hline \multirow{2}{*}{ Formas Base Potenciales } & Lámina & 19 & $2,50 \%$ \\
\hline & Lasca (mayor a $10 \mathrm{~mm}^{2}$ ) & 332 & $43,63 \%$ \\
\hline Total Formas Base Potenciales & & 352 & $46,25 \%$ \\
\hline \multirow{2}{*}{ Instrumentos } & Instrumento & 58 & $7,62 \%$ \\
\hline & Resto de Instrumento & 43 & $5,65 \%$ \\
\hline Total Instrumentos & & 101 & $13,27 \%$ \\
\hline \multirow{3}{*}{ Núcleos } & Núcleo & 8 & $1,05 \%$ \\
\hline & Núcleo agotado & 2 & $0,26 \%$ \\
\hline & Resto de Núcleo & 8 & $1,05 \%$ \\
\hline Total Núcleos & & 18 & $2,37 \%$ \\
\hline Total general & & 761 & $100,00 \%$ \\
\hline
\end{tabular}

Las formas base sobre las que se confeccionan los instrumentos también pueden ser diagnósticas. En este sentido, la utilización de cualquier tipo de soporte para la confección de instrumentos, ya sean lascas, láminas o desechos propiamente dichos, se podría vincular con la falta de estandarización producto del uso de formas previamente descartadas como materia prima. Para este caso, la proporción más alta $(48,51 \%)$ corresponde a formas no determinables dado el grado de formatización de los artefactos, mientras que el siguiente grupo es el de las lascas no diferenciadas (Tabla 4). Las morfologías registradas no parecen destacar ninguna especificidad ni uso generalizado de formas no estandarizadas.

El tamaño de los instrumentos también puede resultar un indicador valioso para evaluar el grado de reactivación o reciclaje de artefactos. En la Fig. 4 puede observarse que la mayoría de los instrumentos formatizados tienen un tamaño chico, que corresponde a una dimensión mayor de entre 20 y $40 \mathrm{~mm}$.

Considerando el grado de conservación (Fig. 5), un $43 \%$ de estas piezas están enteras y un
$24 \%$ se consideraron como fragmentadas. De este modo, si tomamos sólo el grupo de instrumentos formatizados enteros (que conforman un conjunto de 44 piezas) y revisamos las proporciones de las distintas categorías por tamaño, podemos observar que también se destaca claramente el grupo de los tamaños chicos (Fig. 6). Esta preponderancia de tamaños chicos, podría estar marcando una tendencia tecnológica específica, así como también estar vinculada a una alta incidencia de conductas de reactivación, reciclaje de artefactos.

La evidencia de uso de filos naturales puede sugerir un aprovechamiento como instrumentos de todas las morfologías disponibles. Acorde a nuestros análisis, el $25 \%$ del total de las piezas analizadas presentan filos retocados $\mathrm{O}$ potencialmente utilizables, mientras que el restante $75 \%$ corresponde a desechos de talla sin aristas "utilizables".

Si bien el análisis funcional y la búsqueda de microdesgastes serían vías de trabajo importante para avanzar sobre este punto, estos estudios aún están siendo realizados. Sin embargo, el grado de embotamiento de los filos es mensurable con los 
Tabla 3. Tipos de instrumentos registrados (en cursiva se destacan las proporciones más altas).

\begin{tabular}{lc}
\hline \multicolumn{1}{c}{ Tipo probable } & Total \\
\hline Ápice de punta de proyectil & $0,99 \%$ \\
\hline Denticulado & $0,99 \%$ \\
\hline Filo Formatizado & $23,76 \%$ \\
\hline Filos retocados convergentes & $1,98 \%$ \\
\hline Forma no clasificable & $3,96 \%$ \\
\hline Lasca con retoque & $1,98 \%$ \\
\hline Multifunción & $1,98 \%$ \\
\hline Preforma & $6,93 \%$ \\
\hline Punta de proyectil & $4,95 \%$ \\
\hline Punta destacada & $4,95 \%$ \\
\hline Punta destacada y filo formatizado & $0,99 \%$ \\
\hline Punta no destacada (según Aschero) & $0,99 \%$ \\
\hline Raedera & $2,97 \%$ \\
\hline Raedera con dorso & $0,99 \%$ \\
\hline Raspador & $29,70 \%$ \\
\hline Raspador - Multifunción & $0,99 \%$ \\
\hline Raspador con filos laterales retocados & $2,97 \%$ \\
\hline Raspador con muescas de enmangue & $0,99 \%$ \\
\hline Raspador doble & $0,99 \%$ \\
\hline Raspador perimetral & $0,99 \%$ \\
\hline Raspador triangular & $4,95 \%$ \\
\hline Total general & $100,00 \%$ \\
\hline & \\
\hline
\end{tabular}

análisis a ojo desnudo y lupa binocular a partir de caracteres como cicatrices en escalón, retracción de arista, filos abruptos, etc. y pudiendo indicar la reactivación de los filos. Tomando estas variables como criterio de análisis, se definieron cuatro categorías de desgaste de filos: alto, medio, bajo y $\sin$ desgaste.

En la Fig. 7 se presentan los resultados respecto a los niveles de desgaste de filos. En la mayoría de los casos el desgaste se ubica entre las categorías medio y bajo, mientras que casi no aparecen filos con desgaste alto.

Ante una reiterada reutilización de instrumentos, en un marco de reclamación generalizada de restos líticos de ocupaciones anteriores, deberíamos encontrar un alto porcentaje de filos con desgaste alto, es decir,
Tabla 4. Morfologías de la forma base (en cursiva se destacan los porcentajes más altos).

\begin{tabular}{lc}
\hline \multicolumn{1}{c}{ Morfología de la Forma Base } & Total \\
\hline Hoja de arista doble & $1,98 \%$ \\
\hline Hoja de arista simple & $0,99 \%$ \\
\hline Hoja de aristas múltiples & $1,98 \%$ \\
\hline Hoja no diferenciada & $1,98 \%$ \\
\hline Indeterminado & $48,51 \%$ \\
\hline Lasca angular & $6,93 \%$ \\
\hline Lasca con dorso & $0,99 \%$ \\
\hline Lasca de arista simple & $8,91 \%$ \\
\hline Lasca de flanco de núcleo & $0,99 \%$ \\
\hline Lasca no diferenciada & $15,84 \%$ \\
\hline Lasca plana & $0,99 \%$ \\
\hline Lasca primaria & $4,95 \%$ \\
\hline Lasca secundaria & $4,95 \%$ \\
\hline Total general & $100,00 \%$ \\
\hline
\end{tabular}

una marcada tendencia a descartar artefactos que ya no pueden ser reciclados. Sin embargo, los resultados no concuerdan con esta idea, por lo que podríamos estar simplemente ante un panorama de descarte de instrumentos cuando éstos pierden su utilidad, sin que se dedique demasiado esfuerzo en su reciclaje o reformatización.

La evaluación de los tamaños respecto del total de las piezas puede ser informativa a la hora de determinar si se están reutilizando los restos de

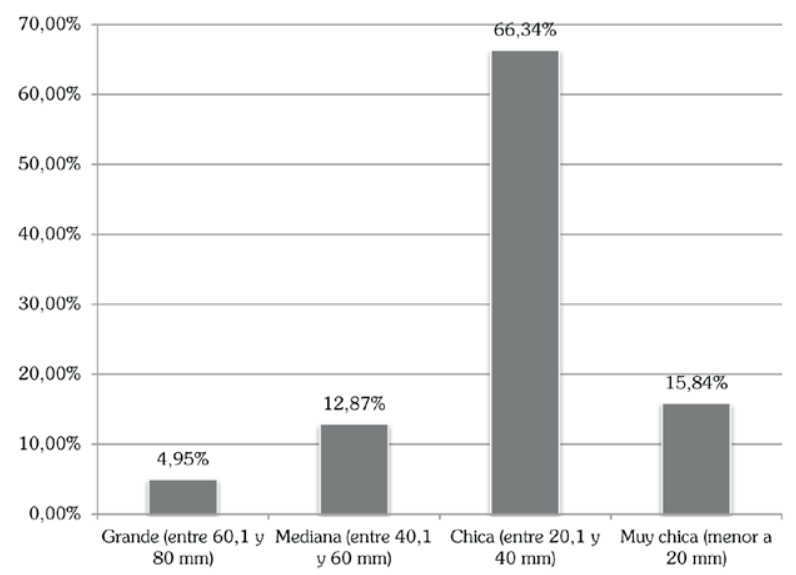

Fig. 4. Categorías por tamaño para los instrumentos formatizados. 


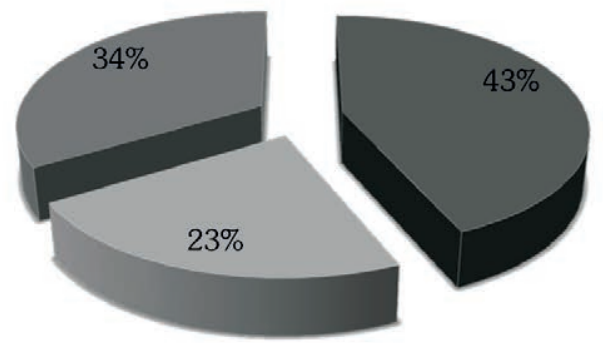

- Entera (falta menos del $5 \%$ )

॥ Fragmentada (falta entre el 5 y $30 \%$ )

— Fragmento (falta más del 30\%)

Fig. 5. Grado de conservación de las piezas correspondientes a instrumentos formatizados.

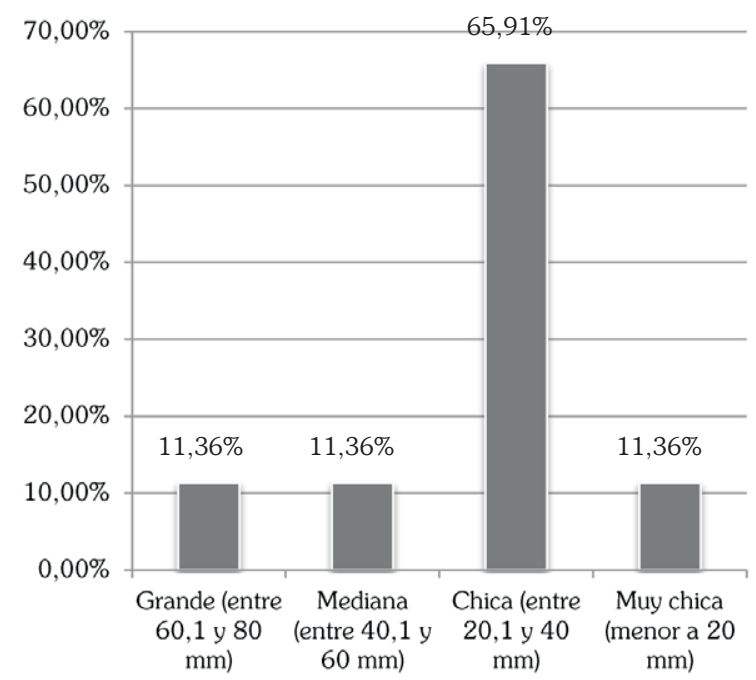

Fig. 6. Categorías por tamaño de los instrumentos enteros formatizados.

talla (tanto desechos, como formas base potenciales $e$ instrumentos formatizados). La Fig. 8 muestra cómo están representadas en este conjunto las categorías por tamaño.

En términos generales esperaríamos que los tamaños -tanto de instrumentos formatizados como de desechos y lascas, por el uso y reactivaciónfueran de tamaños chicos a muy chicos. Los resultados concuerdan con las expectativas para este caso.

Una variable que puede ser indicativa de la maximización de los recursos líticos de tamaños pequeños es la técnica de talla bipolar, ya que permite la manipulación de piezas de tamaños relativamente pequeños. En este conjunto sólo aparecen 3 piezas con evidencias de talla bipolar, y estas corresponden a una lasca, un desecho mediano y un instrumento tipo raspador, por lo que esta técnica no aparece como una herramienta aprovechada significativamente en estas piezas.

Desde un punto de vista tafonómico, procesos postdepositacionales naturales $y$ culturales pueden afectar la superficie de las piezas de manera tal que sea posible distinguir eventos de talla separados cronológicamente. Para esto se consideraron la presencia de pátinas, el grado de erosión de las piezas, la presencia de microfracturas o microlascados.

Los análisis realizados indicaron que el 98 $\%$ de las piezas de este conjunto presenta algún tipo de evidencia de alteración postdepositacional, mientras que sólo un $2 \%$ aparece como no alterada.

En la Fig. 9 se observa que la mayoría de las piezas presentan daños (es decir microfracturas y microlascados como las observadas en la Fig. 10) y abrasión (como la observada en la Fig. 11), o sólo daños. El resto de las alteraciones o sus combinaciones aparecen en bajas proporciones.

Teniendo en cuenta que el sustrato de los sitios es básicamente arenoso, la abrasión probablemente sea el resultado de la incidencia del viento, del desmoronamiento y de la fricción de las

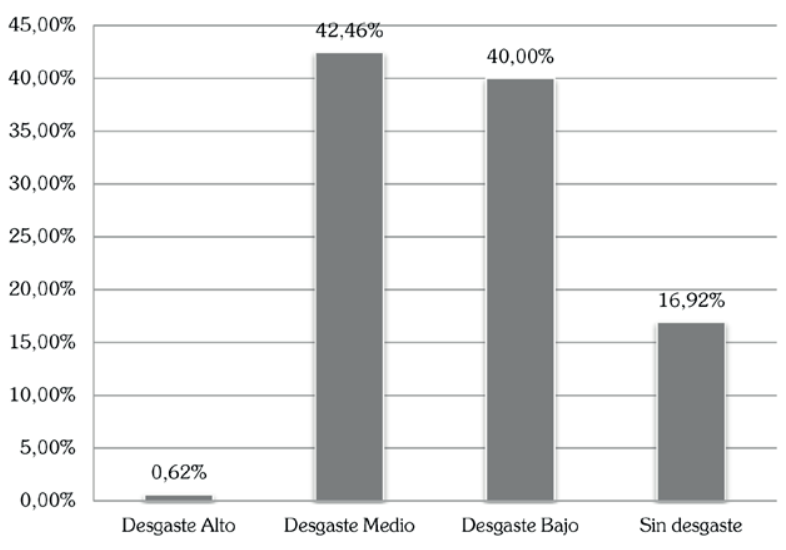

Fig. 7. Niveles de desgaste en los filos en porcentajes. 


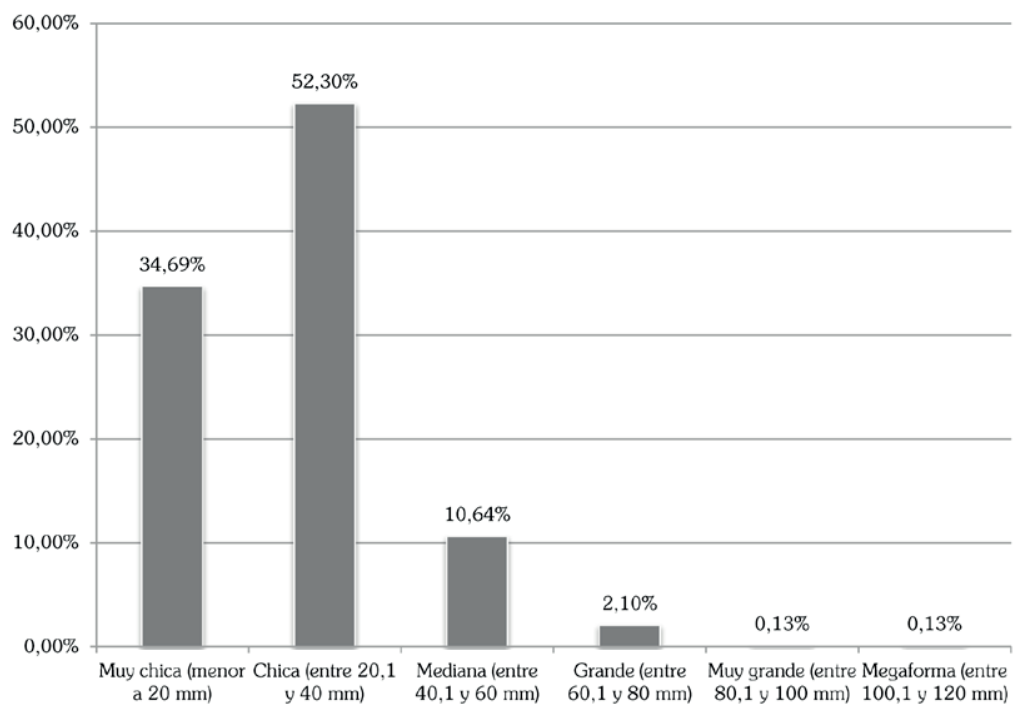

Fig. 8. Categorías por tamaño sobre el total de las piezas analizadas.

piezas con el sustrato. Asimismo, ese movimiento, combinado con el pisoteo de animales y el impacto antrópico, puede generar los microlascados y microfracturas que denominamos daños (Borrazzo, 2004).

Es importante distinguir entonces, entre los diversos tipos de alteración postdepositacionales, para poder diferenciar los que son producto de eventos naturales o antrópicos fortuitos y aquellos que son el resultado de acciones tecnológicas y comportamientos vinculados a la reclamación de restos líticos. Para ello consideramos la ubicación de los daños respecto de la topografía general de las piezas (si sólo están en las aristas o superficies funcionales de la pieza o en cualquier arista o superficie) y qué tan generalizados aparecen.

De este modo pudimos agrupar las piezas en categorías según la génesis probable de sus alteraciones superficiales. Los resultados indicaron que la mayor parte de los restos presenta alteraciones o daños de origen natural o natural combinado con daños funcionales o tecnológicos, mientras que el resto de las categorías se presentan en muy bajas proporciones

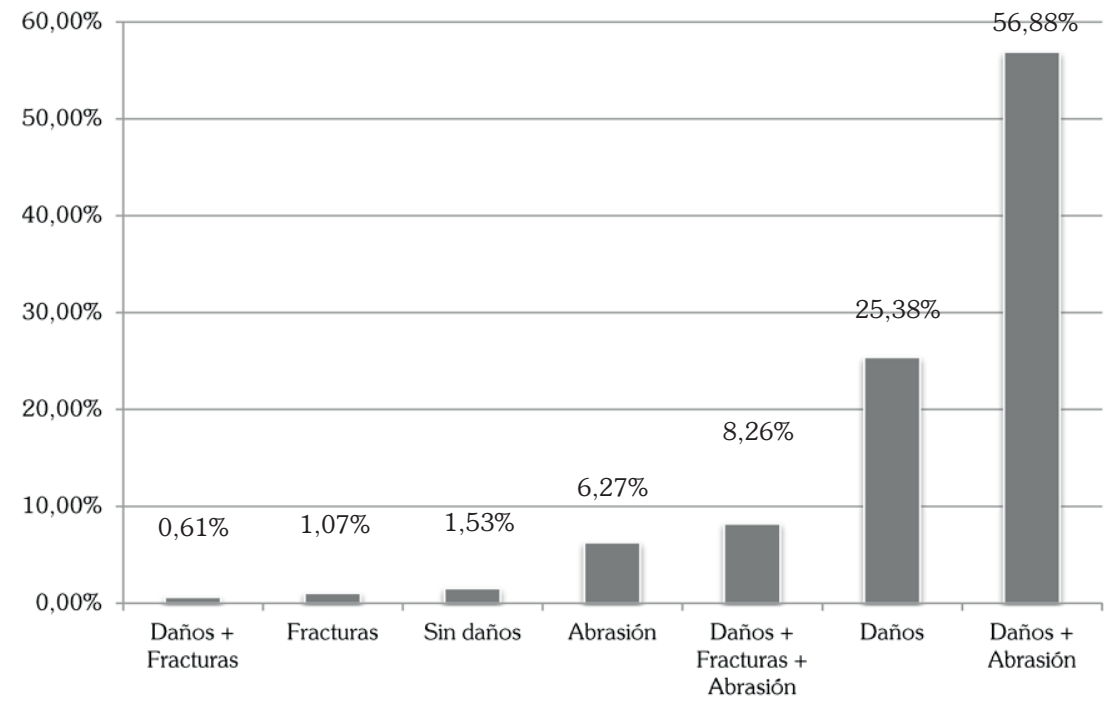

Fig. 9. Daños registrados y sus combinaciones, considerando la superficie total de las piezas. 


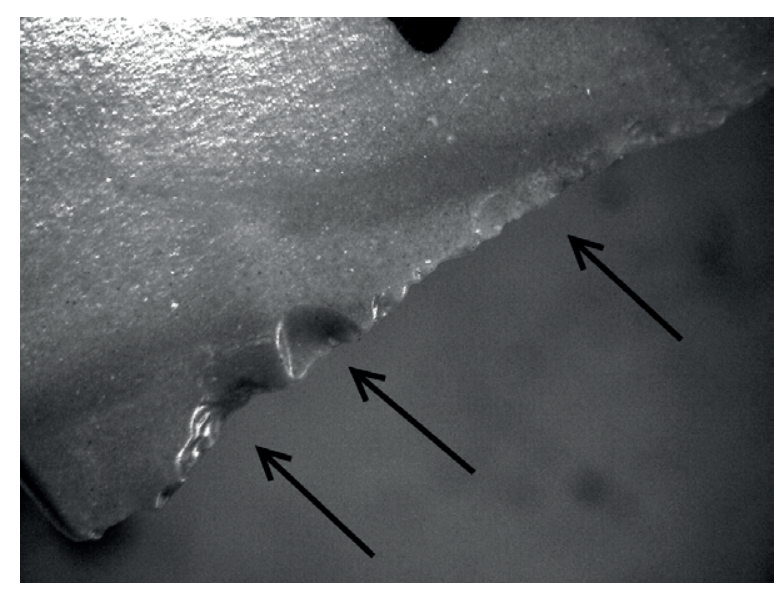

Fig. 10. Arista con daños (microfracturas y microlascados).

(Fig. 12).

La expectativa para este análisis puntual era que los daños naturales aparecieran generalizados en la mayoría de las piezas de este conjunto, con un alto porcentaje de daños tecnológicos y funcionales. Los resultados respaldan esta expectativa. Las Figs. 13, 14, 15 y 16 presentan ejemplos de alteraciones superficiales en distintas aristas o superficies de las piezas.

Desde un punto de vista tecnológico, la aplicación de tratamiento térmico podría indicar comportamientos vinculados a la maximización de

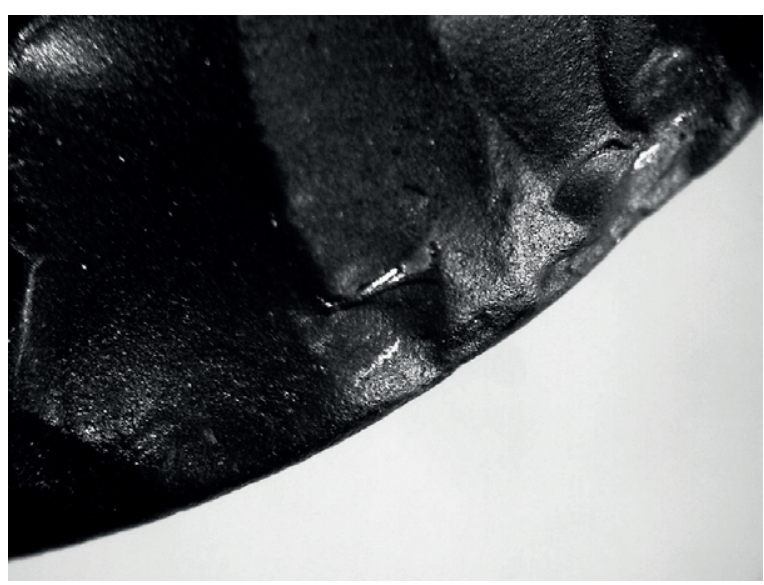

Fig. 11. Arista retocada y muy abradida.

los recursos, en un contexto de reutilización de los restos de talla, teniendo en cuenta que la aplicación de esta técnica mejoraría la calidad para la talla de los materiales líticos. Para este caso es importante señalar que del $11 \%$ de piezas que presentan algún indicio de alteración o daño térmico, casi la mitad presentan evidencias de la aplicación exitosa de tratamiento térmico, determinadas por el lustre o el cambio de color, mientras que el resto presenta evidencias de daño térmico, indicado por la presencia de hoyuelos, rugosidad, agrietamiento y escamaciones (Cueto \& Frank, 2008), tal como

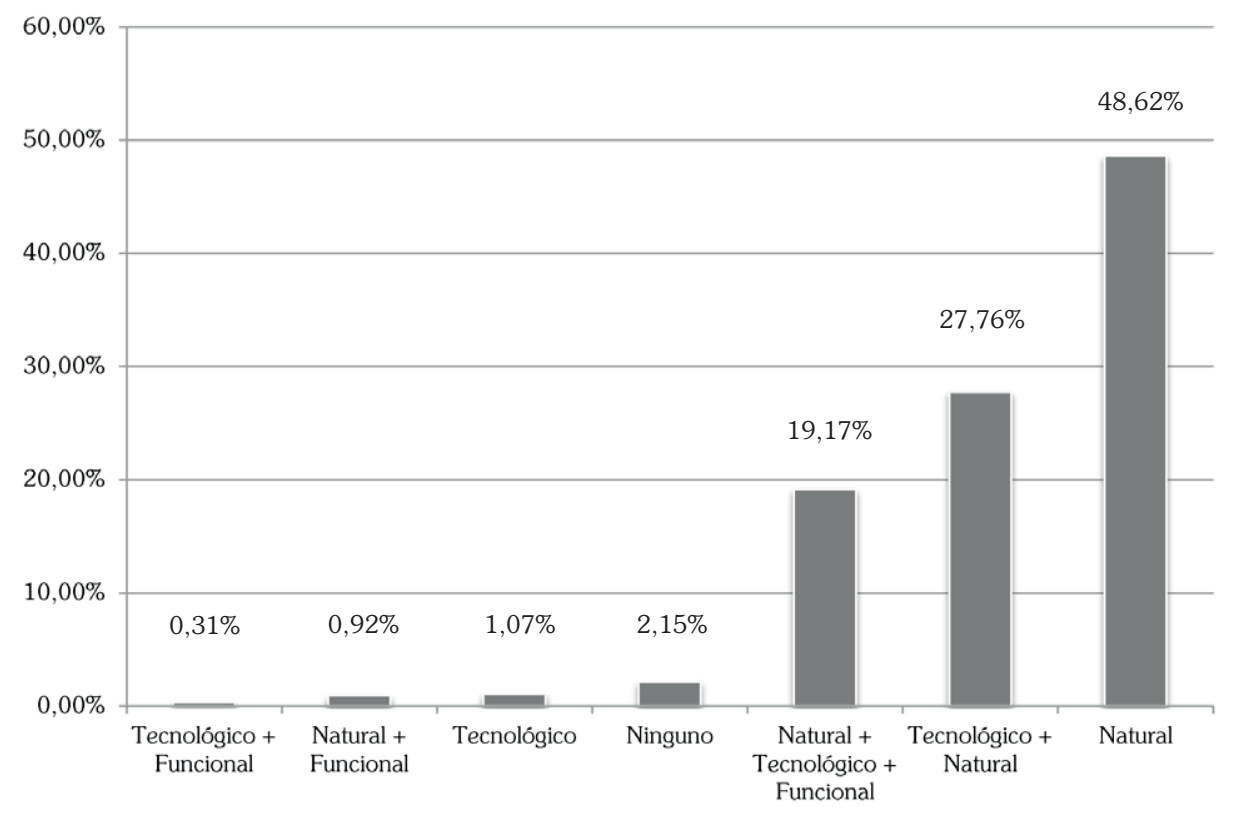

Fig. 12. Proporciones de los distintos tipos de daño y sus combinaciones. 


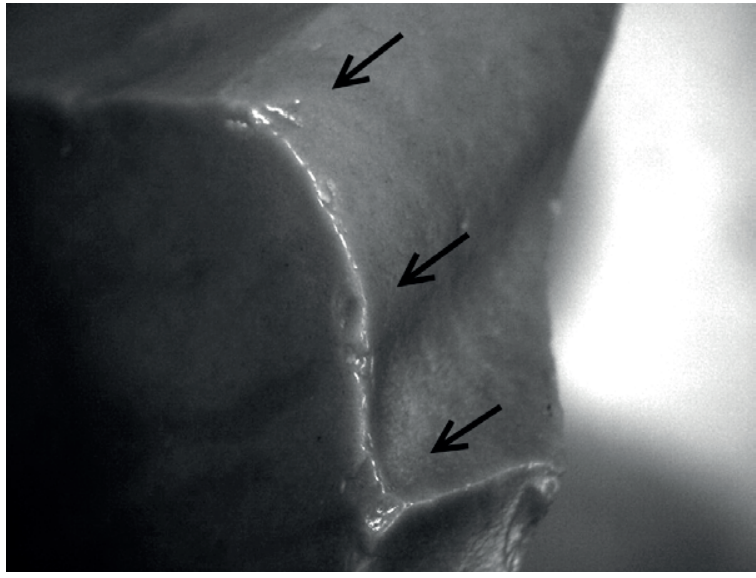

Fig. 13. Daños en arista no utilizable como filo cortante.

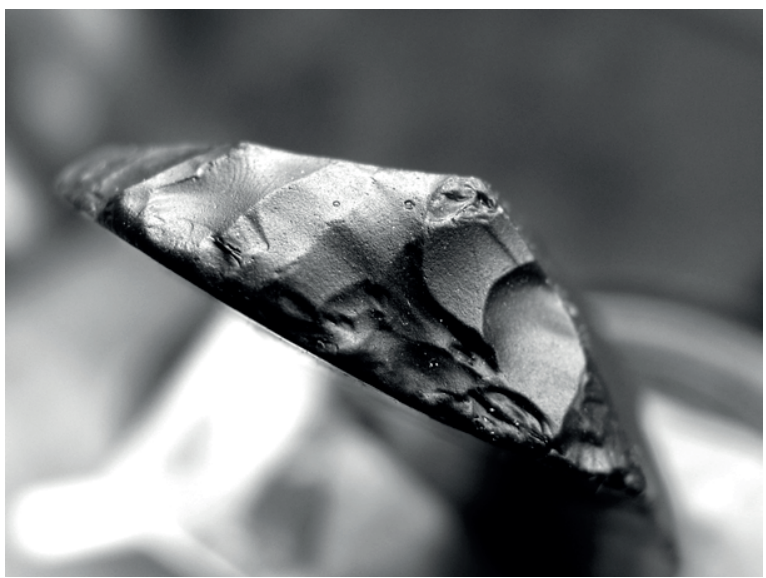

Fig. 15. Raspador sobre obsidiana, con superficie muy abradida.

puede observarse en la Fig. 17. En las figuras 18 y 19 se observan algunos ejemplos de las alteraciones térmicas registradas en las piezas de este conjunto.

Las piezas de este conjunto presentan claras evidencias de alteraciones térmicas o tratamiento térmico, pero en un porcentaje pequeño que resulta poco significativo para considerarlo como el resultado de una estrategia de maximización de

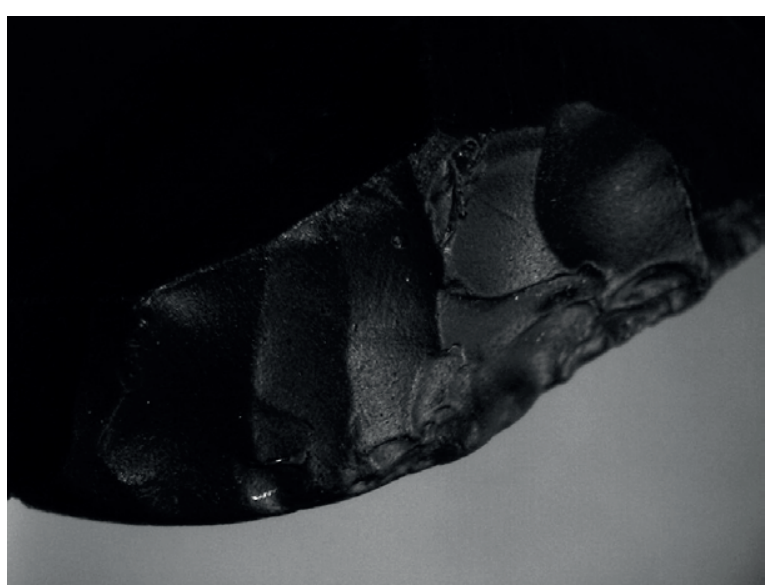

Fig. 14. Filo de raspador abradido y con aristas suavizadas.

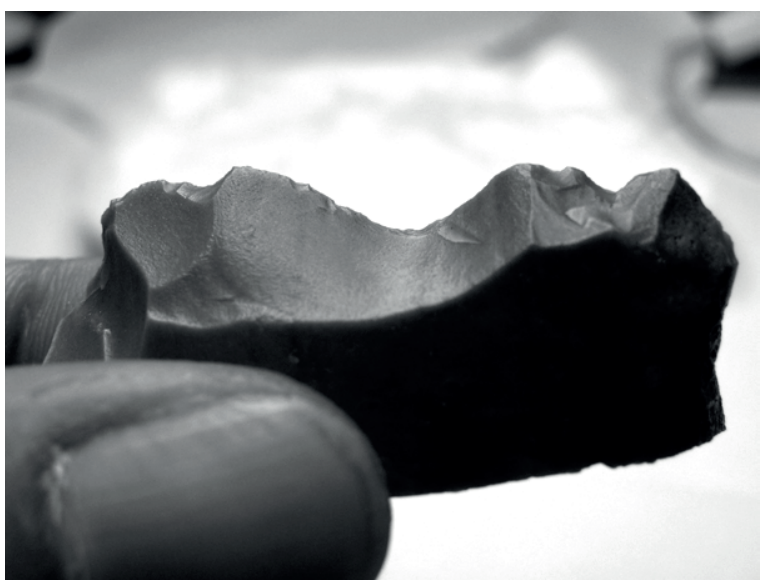

Fig. 16. Pieza con daños en todas sus aristas.

recursos líticos generalizada.

Respecto a la presencia de pátinas, pudimos registrar que un $10 \%$ del conjunto presenta alguna alteración superficial que puede considerarse como pátina, con un brillo característico y claramente distinguible. En la Fig. 20 se muestran algunos ejemplos de piezas con pátina.

La presencia de pátinas y alteraciones

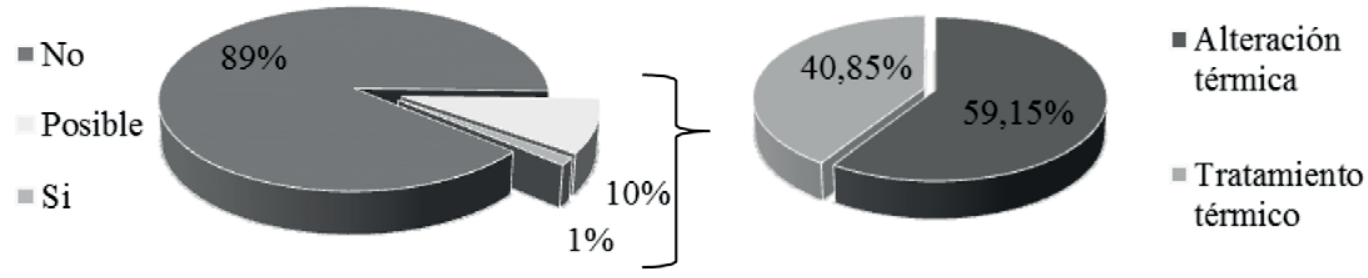

Fig. 17. Presencia de alteración térmica y de tratamiento térmico. 


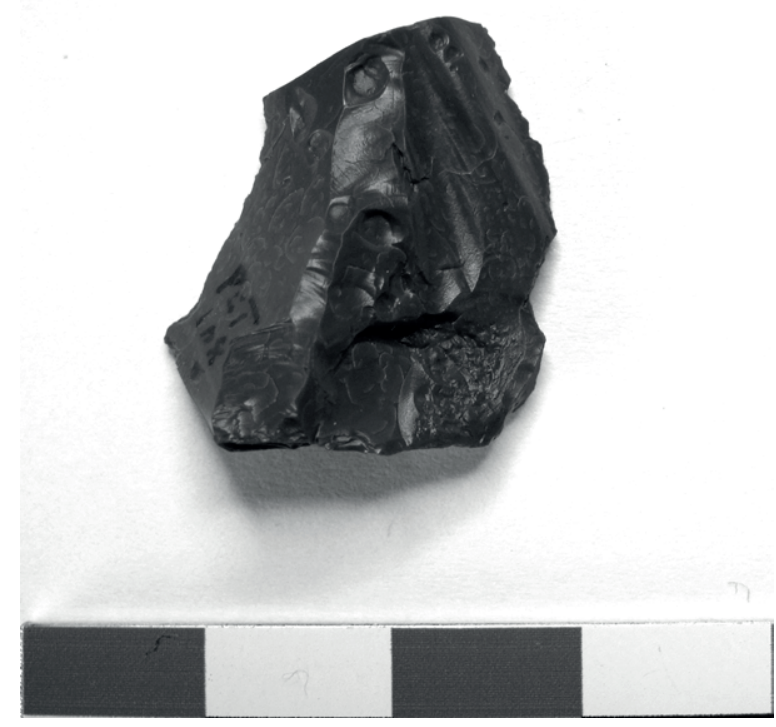

Fig. 18. Presencia de hoyuelos, escamaciones y agrietamientos.

de superficie de las piezas, ya sean naturales o el producto de la aplicación de técnicas de tratamiento térmico, nos sirvieron para identificar eventos diacrónicos de talla, formatización o uso

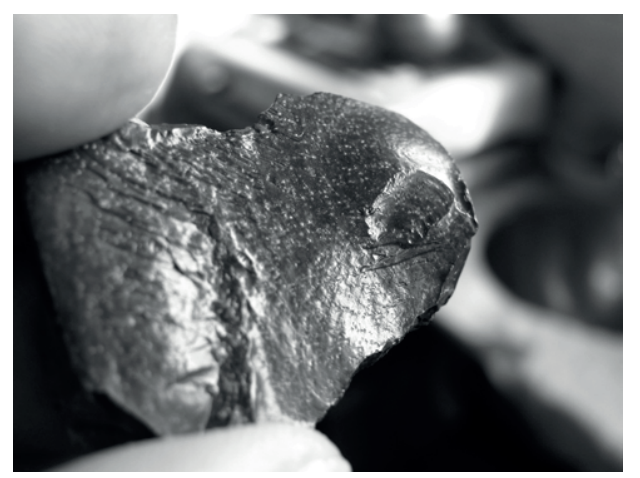

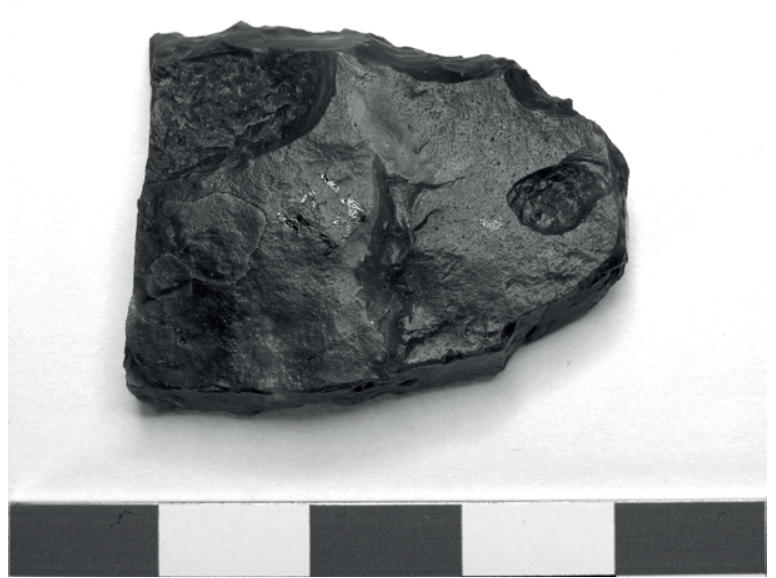

Fig. 19. Presencia de escamaciones y hoyuelos.

probable.

Relevamos de este modo, la presencia de daños "modernos", que se presentan como un negativo o superficie de fractura fresca o menos alterada que el resto de la pieza. Éstos se registraron teniendo en cuenta también su ubicación, discriminando entre los daños presentes sobre los filos naturales o formatizados y los ubicados sobre

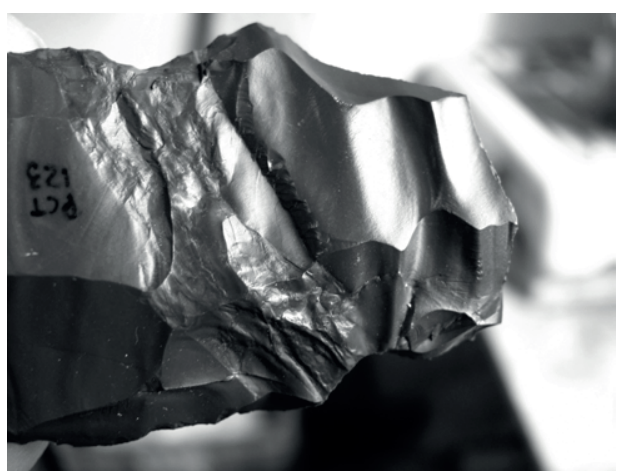

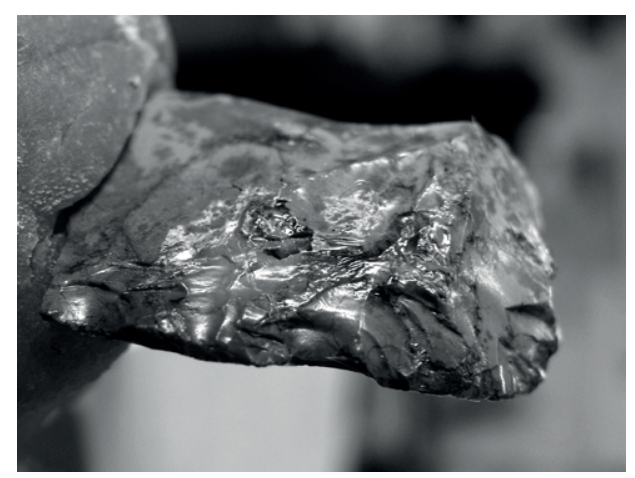

Fig. 20. Algunos ejemplos de piezas con pátinas. 

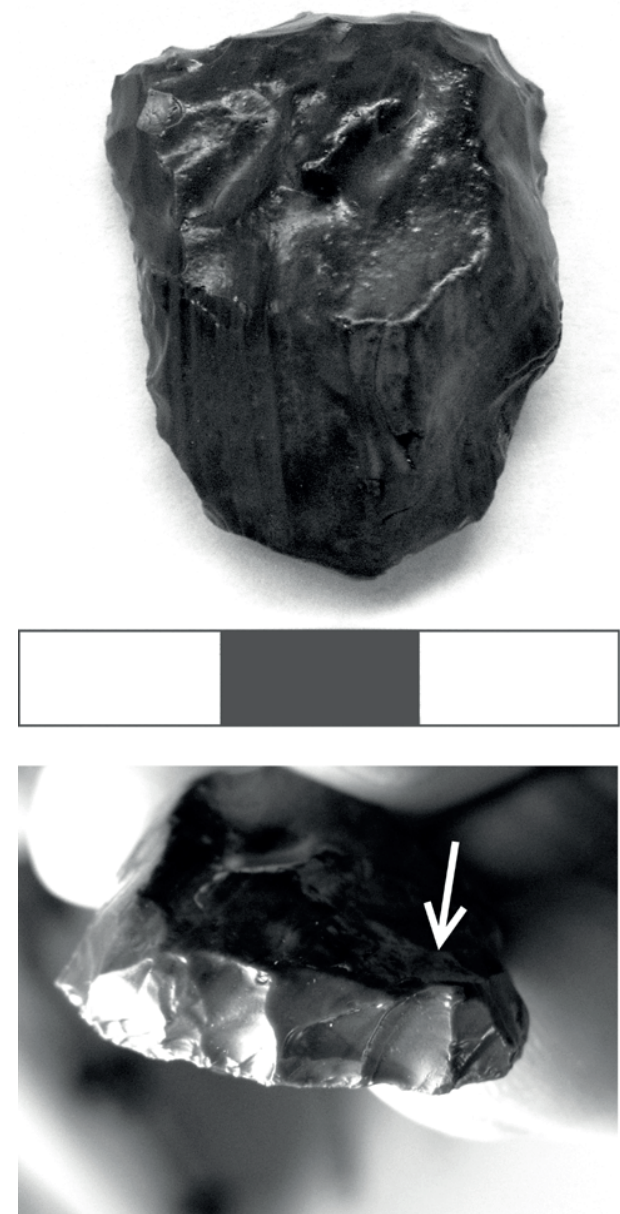

Fig. 21. Raspador de sílice rojo con lascados modernos sobre su filo formatizado. Con las flechas blancas se señalan los negativos "modernos". otras aristas o superficies de la pieza, con el fin de distinguir un daño accidental de un evento de reactivación o re-formatización.

Los resultados mostraron que aproximadamente un $4 \%$ del conjunto total presenta daños "modernos" fuera de los filos o aristas funcionales, lo que conforma una proporción bastante baja. Estos daños suelen aparecer bastante generalizados y ubicados en cualquier parte de la topografía de las piezas y probablemente son accidentales (o no intencionales).

Por otra parte, dentro del grupo de piezas que tienen filos formatizados o potencialmente utilizables, sólo un $7 \%$ presenta daños "modernos" sobre esos filos, de modo que los daños modernos sobre aristas o superficies vinculadas a la reactivación o re-formatización de artefactos, como sucedería en un marco de reclamación y reciclaje de instrumentos, no aparecen en valores significativos para nuestro conjunto. En la Fig. 21 puede observarse un caso de lascados modernos sobre un filo formatizado, los cuales se destacan por una diferencia en el brillo del negativo de extracción que contrasta con la pátina o lustre del resto de la superficie, tanto del área del filo formatizado como de la pieza en general.

Ésta es una de las características que se esperaba encontrar con mayor abundancia en el marco de conductas de reclamación y reciclaje, dada la incidencia de intensos procesos de alteración registrados para esta área y 
para este tipo de sustratos, como se comentó anteriormente.

\section{CONCLUSIONES Y CONSIDERACIONES FINALES}

Los resultados obtenidos a partir del análisis del material lítico nos han permitido cuestionarnos acerca de ciertas dinámicas sociales de interés para la interpretación en arqueología. Los procesos de reocupación del espacio, como hemos podido registrar para la localidad de Punta Medanosa, produjeron la acumulación de gran cantidad de materiales. Esta acumulación puede ser el producto de acciones intencionales o no intencionales, como una forma de litificación del espacio (Martinez, 2002). Dada esta disponibilidad de materiales líticos, que podrían ser considerados como una fuente terciaria de aprovisionamiento (Somonte \& Baied, 2011), es posible que hayan tenido lugar acciones de reclamación (Schiffer, 1991) y en consecuencia, reutilización, (incluyendo reactivación y reciclaje) y/o re-formatización de artefactos líticos. Estos últimos fenómenos, pueden dejar evidencias en las piezas arqueológicas que nos sirvan como elementos diagnósticos para discutir la escala de estas dinámicas tecnológicas (si es que las hubiere) y si pueden ser considerados como una estrategia tecnológica (Nelson, 1991), en un ambiente particular como lo es Punta Medanosa.

Acorde a nuestros objetivos y a partir del análisis de un conjunto de referencia, pudimos definir variables tipológicas, tecnológicas, morfológicas y tafonómicas útiles para indagar acerca de procesos de reutilización y re-formatización de artefactos líticos en el marco de reocupaciones sistemáticas del espacio y de conductas de reclamación. Esta metodología exploratoria de análisis nos permitió reconocer esos caracteres diagnósticos y por lo tanto resultó válida para avanzar sobre nuestra hipótesis de trabajo. No obstante, para contrastar la idea del aprovechamiento de restos de ocupaciones anteriores como fuente de materias primas o de instrumentos formatizados, fue necesario considerar varias líneas de evidencia en forma paralela.

Las fuentes de aprovisionamiento de materias primas líticas del área aún están siendo determinadas, aunque ya se ha avanzado en sectores cercanos en los que se localizaron fuentes primarias y secundarias (Luedtke, 1979; Nami, 1992) de algunas de las materias primas presentes en los conjuntos de Punta Medanosa (Ambrústolo, 2011). Sin embargo, en este trabajo no se han tomado en cuenta las materias primas para los análisis, debido a que consideramos que los procesos sobre los cuales nos estamos cuestionando no dependen directamente de los tipos de materias primas disponibles en el área, sino que nos interesa saber si el cúmulo de materiales líticos generado a través de reiteradas ocupaciones de un mismo espacio, pudo haber sido considerado y utilizado en sí mismo como una fuente de aprovisionamiento.

Los resultados nos han dado una gran cantidad de información y nos permitieron obtener algunas conclusiones relevantes.

Por un lado, los tamaños de los instrumentos formatizados y los tamaños promedio del conjunto en general, pertenecen en su amplia mayoría a las categorías: chico y muy chico, correspondiéndose en este caso con lo esperado para piezas trabajadas y retrabajadas en varias ocasiones. Por otro lado, la presencia diferencial de los tipos de daño también refuerza la idea de que estas piezas pudieron ser reclamadas, reactivadas o re-formatizadas, registrándose daños naturales generalizados en todo el conjunto, y seguidos en importancia $y$ cantidad por los daños tecnológicos y funcionales.

Sin embargo, otra serie de resultados apuntan en sentido contrario. La presencia de núcleos no agotados; el hecho de que la mayor parte de las morfologías de los instrumentos formatizados pertenezcan a formas tipificables, y que aparezca un número muy bajo de instrumentos multifuncionales; que las formas base no presenten ninguna tendencia hacia el uso de morfologías no estandarizadas; o que los filos formatizados o naturales presenten en su mayor parte un desgaste entre medio y bajo, son todas líneas de evidencia que apuntan a que las piezas de este conjunto no fueron recicladas, reactivadas, etc. por lo menos no en una escala amplia o masiva. Se destaca también el hecho de que los denominados "daños modernos" no aparecen en valores significativos en las aristas o superficies vinculadas a la reactivación de instrumentos o en los sectores funcionales de las piezas. Podemos agregar, la ausencia de talla bipolar y la baja presencia de aplicación de 
tratamiento térmico, como dos vías indirectas de acercarnos a la misma problemática y que apuntan en la misma dirección.

Los análisis realizados indican que los eventos de reciclaje o re-formatización sólo aparecen de manera puntual, pero no como tendencias que nos lleven a pensar en una estrategia tecnológica generalizada para esta zona en particular.

Nuestra hipótesis de trabajo se planteó por una cuestión de disponibilidad simple, es decir "si esta materia prima lítica está disponible $y$ es abundante, debe haberse aprovechado". Sin embargo los análisis indican que no sucedió así, y por lo tanto nos interesa cuestionarnos, al menos tentativamente, acerca de qué factores podrían estar dando cuenta de nuestros hallazgos.

La visibilidad de los sitios y de los restos es una vía importante a tener en cuenta ya que acorde a los habitantes de la zona, este sector fue deforestado a mediados del siglo XX para la obtención de leña, por lo que los materiales arqueológicos no habrían estado tan expuestos en momentos anteriores. Asimismo, los procesos de formación de sitio inciden de forma tal, que descubren, desmoronan y dispersan los restos contenidos en las lentes de valvas, por lo que resulta difícil determinar si esta dispersión que hoy vemos en el área de estudio, fue tan importante en otro momento en donde la vegetación podría haber funcionado como fijadora de los médanos (tarea que hoy cumplen las lentes de valvas arqueológicas) o preservando de algún modo las concentraciones de material.

Por otro lado, las investigaciones realizadas hasta el momento indican que los concheros corresponderían a basureros o zona de descarte de materiales y, en consecuencia, no conformarian necesariamente un recurso disponible, sea por accesibilidad o por su significado social. También podemos cuestionarnos sobre la posibilidad de que haya una elección o decisión de no utilizar esos materiales o herramientas que fueron dejados previamente por otros grupos humanos (antepasados o un "otro social"). En este punto pueden estar interviniendo variables vinculadas con lo simbólico y con el valor social de esos restos para los grupos que aprovecharon la costa de Santa Cruz.

Finalmente, es interesante considerar cómo los arqueólogos categorizamos un paisaje y definimos la disponibilidad, accesibilidad y potencial de aprovechamiento de las materias primas; por qué consideramos que ellas debieron o no ser utilizadas por los grupos humanos en el pasado quiénes, con seguridad, han tenido su propio modo de categorizar y mesurar el valor de los restos dispersos o disponibles en esta zona particular de la costa norte de Santa Cruz. Hoy el paisaje de la localidad de Punta Medanosa, se nos manifiesta a nosotros los arqueólogos con una riqueza tal, que nos "obliga" a pensar que esos materiales debieron ser utilizados por las poblaciones de cazadores recolectores del Holoceno medio y tardío que aprovecharon los recursos costeros de esta zona. Cabe preguntarnos cuánta "subjetividad arqueológica" le estamos atribuyendo a estos paisajes, que nos entusiasman con su riqueza por nuestra particular forma de mirar el mundo.

Sin embargo, si una pregunta nos puede llevar a revisar nuestras metodologías y a cuestionarnos acerca de una gran diversidad de variables, la pregunta no sólo es válida, sino que buscar su respuesta cobra importancia, para lograr avances metodológicos de nuestra labor arqueológica en el presente y para avanzar en el conocimiento de las conductas de los grupos humanos del pasado.

\section{AGRADECIMIENTOS}

A todo el Equipo de Arqueología de la Costa norte de Santa Cruz, los que están y los que no están. A los comentarios de la Dra. Alicia Castro y del Dr. Luciano Prates, así como los de los evaluadores. A la UNLP por permitirme desarrollar mis actividades de investigación como becaria de esta institución. Estos trabajos se realizaron en el marco de los proyectos PIP CONICET - Código 11220090100721 y "Estudios arqueológicos regionales para definir la amplitud de los rangos de acción de grupos cazadores-recolectores que usaron la Costa norte de Santa Cruz. Patagonia Argentina" UNLP - Código 11/N594, ambos dirigidos por la Dra. Castro.

\section{BIBLIOGRAFÍA}

Ambrústolo, P. (2011). Estudio de las estrategias de aprovisionamiento y utilización de los recursos líticos por grupos cazadores recolectores en la costa norte de 
Santa Cruz (Patagonia Argentina). Tesis doctoral, Universidad Nacional de La Plata.

Aschero, C. (1975). Ensayo para una clasificación morfológica de artefactos líticos aplicada a estudios tipológicos comparativos. CONICET. Buenos Aires, Argentina.

Aschero, C. (1983). Ensayo para una clasificación morfológica de artefactos líticos. Apéndices A - C. MS. Cátedra de Ergología y Tecnología. FILO - UBA. Buenos Aires, Argentina.

Borrazzo, K. (2004). Hacia una tafonomía lítica: el análisis tafonómico y tecnológico de losconjuntos artefactuales líticos de superficie provenientes de los loci SanGenaro 3 y 4 (Bahía San Sebastián-Tierra del Fuego, Argentina). Tesis de licenciatura en Ciencias Antropológicas, Universidad de Buenos Aires.

Castro, A. S., Moreno, J. E., Zubimendi, M. A., Andolfo, M. d., Videla, B., Ambrústolo, P., . . Sergio. (2007). Cronología de la ocupación humana en la costa norte de Santa Cruz: actualización de datos radiocarbónicos. En Varios, F. Morello, M. Martinic, A. Prieto, \& G. Bahamonde (Eds.), Arqueología de Fuego-Patagonia. Levantando piedras, desenterrandohuesos...y develando arcanos. Punta Arenas: Ediciones CEQUA.

Castro, A. S., Zubimendi, M. A., \& Ambrústolo, P. (2011). Archaeological littoral sites on the northern coast of Santa Cruz: Valuable evidence of sea level changes on the continental Patagonian coasts (Argentina). Quaternary International, 245(1), 111-121.

Castro, A., Moreno, E., Andolfo, M., Gimenez, R., Peña, C., Mazzitelli, L. C., . . . Ambrústolo, P. (2003). Análisis distribucionales en la costa de Santa Cruz (Patagonia Argentina): alcances y resultados. Magallania, 31, 6994.

Castro, A., Moreno, E., Zubimendi, M., Andolfo, M., Videla, B., Ambrústolo, P., . . . Mazzitelli, L. C. (2005). Cronología de la ocupación humana en la costa norte de Santa Cruz: actualización de datos radiocarbónicos. En Arqueología de Fuego-Patagonia - Levantando piedras, desenterrando huesos...y develando arcanos (págs. 527-540). Punta Arenas: Ediciones CEQUA.

Church, T. (1995). Terms in lithic resource studies. Lithic re- source studies: a source for archaeologist. Lithic Technology. Special Publication, Department of Antrhopology, 3, 9-25.

Cueto, M., \& Frank, A. (2008). Tratamiento térmico de artefactos líticos: estudios experimentales. En A. Austral \& M. (Eds.), Problemáticas de la Arqueología Contemporánea (págs. 375-384). Río Cuarto: Universidad Nacional de Río Cuarto.

Luedtke, B. (1979). The identification of sources of chert artifacts. American Antiquity 44, 744-756.

Martinez, G. (2002). Organización y cambio en las estrategias tecnológicas. Un caso arqueológico e implicaciones conductuales para la evolución de las sociedades cazadoras-recolectoras Pampeanas. En G. Martinez \& L. Lanata (Eds.), Perspectivas Integradoras entre Arqueología y Evolución. Teoría, Métodos Casos de Aplicación (págs. 121-156). Olavarría: Serie Teórica del INCUAPA. Vol. 1. FACSO-UNCPBA.

Nami, H. (1992). El subsistema tecnológico de la confección de instrumentos líticos y la explotación de los recursos del ambiente: Una nueva vía de aproximación. Shincal 2, 33-53.

Nelson, M. (1991). The Study of Tecnological Organization. En M. Schiffer (Ed.), Archaeological Method and Theory (págs. 57-100). Tucson: The University of Arizona Press.

Paunero, R., \& Castro, A. (2001). Análisis lítico y funcionalidad del componente inferior del Sitio Cueva 1, localidad arqueológica Cerro Tres Tetas, provincia de Santa Cruz, Argentina. En Anales del instituto de la Patagonia Serie Ciencias Humanas 29, 189-206.

Schiffer, M. B. (1990). Contexto arqueológico y contexto sistémico. Boletín de Antropología Americana 22, 81-93.

Schiffer, M. B. (1991). Los procesos de formación del registro arqueológico. Boletín de Antropología Americana 23, 39-45.

Somonte, C., \& Baied, C. (2011). Recursos Líticos, aprovisionamiento y aspectos temporales de fuentes de abastecimiento en Amaicha del Valle, Tucumán, Argentina. Comechingonia [online], 14(1), 97-113. 